\title{
The efficacy and safety of different pharmacological interventions for patients with advanced biliary tract cancer: A network meta-analysis
}

\author{
Xin-Fang Sun ${ }^{1, *}$, Zhi-Kuan He ${ }^{1, *}$, Jin-Ping Sun ${ }^{1}$, Quan-Xing $\mathbf{G e}^{1}$ and Er-Dong Shen ${ }^{2}$ \\ ${ }^{1}$ Department of Gastroenterology, Henan University Huaihe Hospital, Kaifeng, 475000, Henan, China \\ ${ }^{2}$ Department of Oncology, The First People's Hospital of Yueyang, Yueyang, 414000, Hunan, China \\ *These authors have contributed equally to this work \\ Correspondence to: Quan-Xing Ge, email: cdcgehe@163.com \\ Er-Dong Shen, email: mingli2006_2009@126.com \\ Keywords: biliary tract cancer, chemotherapy treatments, network meta-analysis, efficacy, safety \\ Received: April 27, $2017 \quad$ Accepted: July 25, $2017 \quad$ Published: August 24, 2017 \\ Copyright: Sun et al. This is an open-access article distributed under the terms of the Creative Commons Attribution License 3.0 \\ (CC BY 3.0), which permits unrestricted use, distribution, and reproduction in any medium, provided the original author and source \\ are credited.
}

\section{ABSTRACT}

Biliary tract cancer (BTC) is the second common cancer in liver cancer. Chemotherapy is the mainstay of treatments for patients with advanced or metastatic disease, while fluorouracil (FU)-based and gemcitabine (GEM)-based treatments are most widely applied. This NMA aimed to figure out whether the addition of platinum (PLA) and target agents (TAR) can influence the efficacy and safety of standard chemotherapy. Network meta-analysis (NMA) was conducted based on the records from PubMed, Embase and Cochrane. Eligible data was extracted from available qualified trials and outcomes. Software R 3.2.3 and STATA 13.0 were used to conduct the Bayesian NMA, calculating odds ratios (ORs) and hazard ratios (HRs) with $95 \%$ credible interval ( $\mathrm{CrI}$ ) to evaluate different treatments.Almost all treatments were superior to best supportive care (BSC) and FU in terms of 1-OS, 2-OS and 1-PFS. GEM+PLA and GEM+PLA+TAR exhibited better efficacy than most treatments in 1-OS, 2-OS and 1-PFS, and yielded better results than BSC and GEM+FU in terms of 2-PFS. Most drug-containing treatments reported higher overall response rate (ORR) than BSC. GEM and GEM+FU were associated with a higher risk of neutropenia and thrombocytopenia compared to FU, FU+PLA and GEM+PLA. No statistical difference was detected in terms of nausea and vomiting.GEM+PLA and GEM+PLA+TAR were both efficacious and were associated with fewer adverse events. In conclusion, the addition of PLA can significantly improve the efficacy of FU and GEM-based treatments, and the addition of TAR to GEM+PLA can contribute to further improvement, but with a mild increase of adverse events.

\section{INTRODUCTION}

Biliary tract cancer (BTC), including gallbladder cancer (GBC), intrahepatic cholangiocarcinoma (ICC), extrahepatic cholangiocarcinoma (ECC) and hilar cholangiocarcinoma (HCC), is the second common tumor in liver cancer reports. Although not popular in western countries, the occurrence rate of BTC was particularly high in Southeast Asia [1]. The only way to cure BTC is surgical resection. However, as it is hard to identify at its early stage, most patients are diagnosed with unresectable advanced BTC, with a median overall survival of only 16 months [2]. According to Yang et al. [3], 70\% ICC cases are unresectable at the time of diagnosis.

Chemotherapy is now the mainstay of treatment for BTC, and gemcitabine (GEM) and fluorouracil (FU) based chemotherapy treatments have been proved to be particularly 
effective compared to best supportive care (BSC) [4]. A study conducted by Ducreux et al. showed that the response rate of patients treated with 5-FU based chemotherapy reached $30 \%$ [5]. Moreover, it was found recently that the addition of platinum (PLA) to standard chemotherapy can further improve survival without substantial toxicity. For example, a study conducted by Valle et al. reported that the addition of cisplatin (CIS) to GEM can greatly improve overall survival (OS) and progression-free survival (PFS) of patients with advanced BTC [6].

In addition to platinum drugs, targeted drugs (TAR) were also introduced in standard chemotherapy to improve efficacy while reducing side effects. Targeted agents, such as epidermal growth factor receptor (EGFR) and vascular endothelial growth factor (VEGF) regulated the growth and proliferation of biliary cell, thus exhibited encouraging antitumor activity [7]. A study conducted by Gruenberger et al. suggested that the addition of cetuximab to GEM plus oxaliplatin (OXA) yielded better results in terms of response rate and adverse events [8].

However, despite the reported advantages of additional drugs, some studies did not seem to support those results. For instance, a trial conducted by Chen et al. reported the absence of statistical difference between targeted drugs plus GEM+PLA and GEM+PLA [9]. Even the effect of platinum was to some extent denied according to the results of another study [10]. Thus, no definite conclusion was drawn. Moreover, there are no references to facilitate choices among different chemotherapy treatments. In order to address the issues above, this NMA was designed to evaluate different chemotherapy treatments from mainly randomized controlled trials (RCTs) based on their performance on efficacy and safety outcomes targeting patients with advanced BTC.

\section{RESULTS}

\section{Literature selection results}

Initially, 634 records were retrieved through the electronic databases mentioned above and one additional record was found from reviews. As shown in Figure 1, after removing 108 duplicates and 354 irrelevant records, investigators read the full text of the remaining articles and excluded another 155 articles due to: 1) the disease did not match; 2) relevant outcomes were not reported and 3 ) treatments cannot form a network (insufficient network). In the end, 18 records with a total of 2,471 patients were included in this NMA [9, 11-27]. The network plot illustrated the comparison among 7 drugincluding treatments and BSC and all the drug-including treatments were based on either FU or GEM (Figure 2). As shown in Table 1 , most trials included a follow-up period of more than 2 years, which to some degree guarantees the reliability of results in this NMA.

\section{Overall survival}

Results concerning OS were presented in Table 2 and Figure 3. In terms of 1-OS, except for FU, all treatments exhibited better efficacy than BSC (FU+PLA: $\mathrm{HR}=0.34, \quad 95 \% \mathrm{CrI}=0.20-0.58 ; \quad \mathrm{GEM}: \quad \mathrm{HR}=0.58$, $95 \% \mathrm{CrI}=0.39-0.85 ; \quad \mathrm{GEM}+\mathrm{FU}: \quad \mathrm{HR}=0.54, \quad 95 \% \mathrm{CrI}=$ 0.36-0.82; $\quad$ GEM+PLA: $\quad \mathrm{HR}=0.29, \quad 95 \% \mathrm{CrI}=0.18-$ 0.46 ; GEM+PLA+TAR: $\mathrm{HR}=0.25, \quad 95 \% \mathrm{CrI}=0.14-$ 0.44). Besides, GEM+PLA and GEM+PLA+TAR were superior to most treatments, including GEM+FU $(\mathrm{HR}=0.53,95 \% \mathrm{CrI}=0.39-0.72 ; \mathrm{HR}=0.46,95 \% \mathrm{CrI}=0.30$ 0.72 , respectively), GEM $(\mathrm{HR}=0.50,95 \% \mathrm{CrI}=0.30$ $0.83 ; \quad \mathrm{HR}=0.44,95 \% \mathrm{CrI}=0.24-0.79), \quad \mathrm{FU} \quad(\mathrm{HR}=0.34$, $95 \% \mathrm{CrI}=0.21-0.54 ; \mathrm{HR}=0.30,95 \% \mathrm{CrI}=0.17-0.53)$, while FU turned out to be the worst choice for its inferiority to most treatments. As for 2-OS, treatments containing PLA showed better performance than BSC (FU+PLA: $\mathrm{HR}=0.47,95 \% \mathrm{CrI}=0.27-0.82 ; \mathrm{GEM}+\mathrm{PLA}: \mathrm{HR}=0.40$, $95 \% \mathrm{CrI}=0.24-0.67 ; \quad \mathrm{GEM}+\mathrm{PLA}+\mathrm{TAR}: \quad \mathrm{HR}=0.37$, $95 \% \mathrm{CrI}=0.21-0.64) . \mathrm{GEM}+\mathrm{PLA}$ and GEM+PLA+TAR yielded better results than $\mathrm{GEM}(\mathrm{HR}=0.62,95 \% \mathrm{CrI}=0.49$ $0.79 ; \mathrm{HR}=0.57,95 \% \mathrm{CrI}=0.40-0.80$, respectively) and $\mathrm{FU}$ $(\mathrm{HR}=0.41,95 \% \mathrm{CrI}=0.26-0.62 ; \mathrm{HR}=0.37,95 \% \mathrm{CrI}=0.23-$ $0.60)$. Similar to 1-OS, FU exhibited the worst performance of all drug-containing treatments.

\section{Progression free survival}

Also as was shown in Table 2 and Figure 3, four drug-containing treatments, including FU+PLA, $\mathrm{GEM}+\mathrm{FU}, \mathrm{GEM}+\mathrm{PLA}$ and GEM+PLA+TAR showed better performance than $\mathrm{BSC}(\mathrm{HR}=0.30,95 \% \mathrm{CrI}=0.18$ $0.51 ; \quad \mathrm{HR}=0.46, \quad 95 \% \mathrm{CrI}=0.28-0.74 ; \quad \mathrm{HR}=0.30$, $95 \% \mathrm{CrI}=0.18-0.48 ; \mathrm{HR}=0.24,95 \% \mathrm{CrI}=0.14-0.40)$ with respect to $1-\mathrm{PFS}$. Plus, treatments containing PLA, including FU+PLA, GEM+PLA and GEM+PLA+TAR were superior to those without PLA, including FU $(\mathrm{HR}=0.37,95 \% \mathrm{CrI}=0.26-0.53 ; \mathrm{HR}=0.37,95 \% \mathrm{CrI}=0.28$ $0.49 ; \mathrm{HR}=0.30,95 \% \mathrm{CrI}=0.21-0.42), \mathrm{GEM} \quad(\mathrm{HR}=0.55$, $95 \% \mathrm{CrI}=0.34-0.88 ; \quad \mathrm{HR}=0.54, \quad 95 \% \mathrm{CrI}=0.36-0.83$; $\mathrm{HR}=0.44,95 \% \mathrm{CrI}=0.28-0.69), \quad \mathrm{GEM}+\mathrm{FU} \quad(\mathrm{HR}=0.66$, $95 \% \mathrm{CrI}=0.51-0.84 ; \quad \mathrm{HR}=0.65, \quad 95 \% \mathrm{CrI}=0.56-0.75$; $\mathrm{HR}=0.53,95 \% \mathrm{CrI}=0.42-0.66)$ and $\mathrm{GEM}+\mathrm{TAR}(\mathrm{HR}=0.49$, $95 \% \mathrm{CrI}=0.27-0.88 ; \quad \mathrm{HR}=0.48, \quad 95 \% \mathrm{CrI}=0.28-0.84$; $\mathrm{HR}=0.39,95 \% \mathrm{CrI}=0.22-0.70)$. As for 2-PFS, GEM+PLA and GEM+PLA+TAR showed higher efficacy than BSC $(\mathrm{HR}=0.38,95 \% \mathrm{CrI}=0.18-0.82 ; \mathrm{HR}=0.33,95 \% \mathrm{CrI}=0.14-$ $0.75)$ and $\mathrm{GEM}+\mathrm{FU} \quad(\mathrm{HR}=0.59,95 \% \mathrm{CrI}=0.43-0.82$; $\mathrm{HR}=0.51,95 \% \mathrm{CrI}=0.33-0.79)$.

\section{Overall response rate and disease control rate}

In terms of overall response rate (ORR) (Table 2 and Figure 4), most treatments, including FU+PLA, $\mathrm{GEM}+\mathrm{FU}, \mathrm{GEM}+\mathrm{PLA}$ and GEM+PLA+TAR were significantly better than $\mathrm{BSC}(\mathrm{OR}=27.66,95 \% \mathrm{CrI}=3.25$ - 
572.49; $\mathrm{OR}=14.88,95 \% \mathrm{CrI}=1.73-214.86 ; \mathrm{OR}=20.29$, $95 \% \mathrm{CrI}=2.64-361.41 ; \mathrm{OR}=40.85,95 \% \mathrm{CrI}=4.85-780.55)$. Besides, the addition of TAR to GEM+PLA improved the corresponding ORR $(\mathrm{OR}=1.99,95 \% \mathrm{CrI}=1.08-3.78)$. With respect to disease control rate (DCR), GEM+FU and GEM+PLA+TAR exhibited better results than FU $(\mathrm{HR}=8.00,95 \% \mathrm{CrI}=2.08-35.52 ; \mathrm{OR}=5.93,95 \% \mathrm{CrI}=1.23$ 29.96), and similarly, TAR improved the efficacy of $\mathrm{GEM}+\mathrm{PLA}(\mathrm{OR}=1.68,95 \% \mathrm{CrI}=1.07-2.80)$.

\section{Adverse events (grade $\geq 3$ )}

As shown in Table 3 and Figure 4, GEM and GEM+FU were more likely to cause neutropenia compared with FU $(\mathrm{OR}=13.46,95 \% \mathrm{CrI}=2.18-88.23$; $\mathrm{OR}=27.39, \quad 95 \% \mathrm{CrI}=7.32-132.95) \quad$ and $\mathrm{FU}+\mathrm{PLA}$ $(\mathrm{OR}=31.50, \quad 95 \% \mathrm{CrI}=1.97-1863.11 ; \quad \mathrm{OR}=65.37$, $95 \% \mathrm{CrI}=5.050-3261.69)$, while the addition of PLA seemed to offset this effect (GEM+PLA vs. GEM:

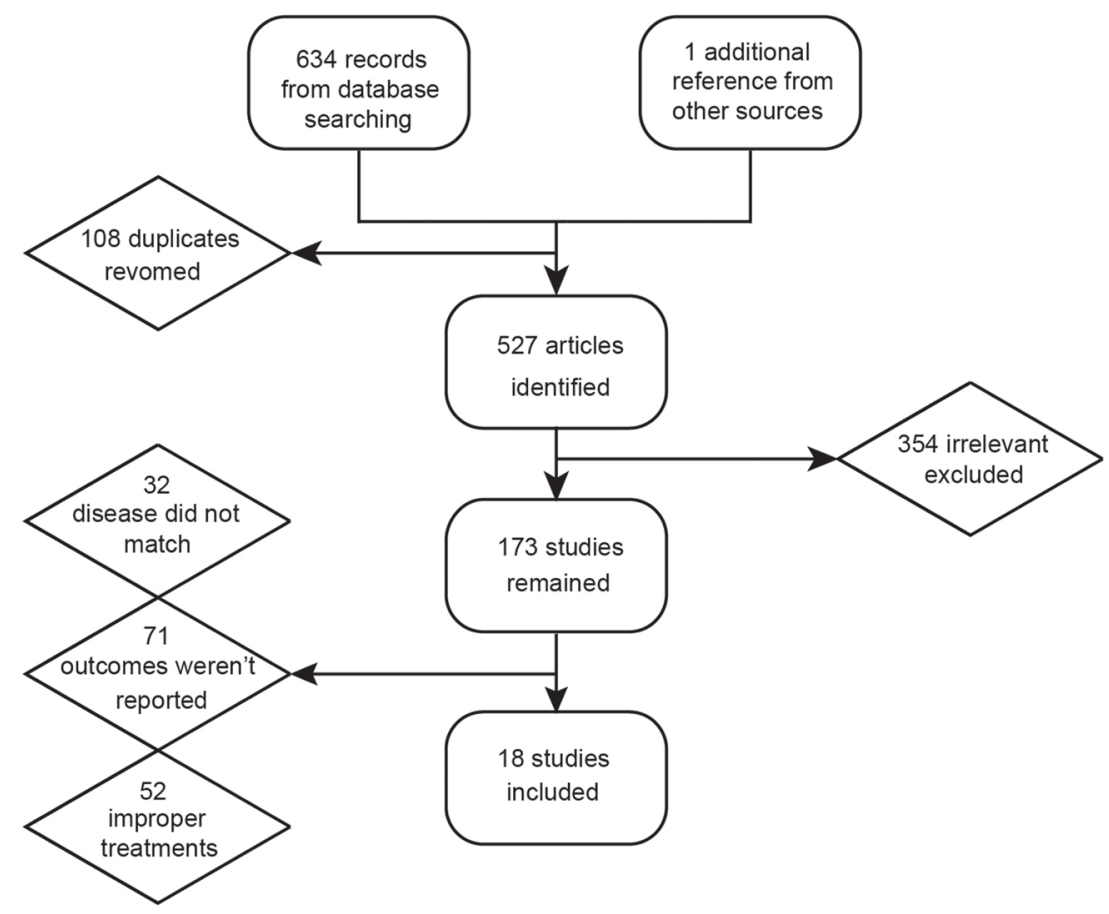

Figure 1: Flow chart of study selection.

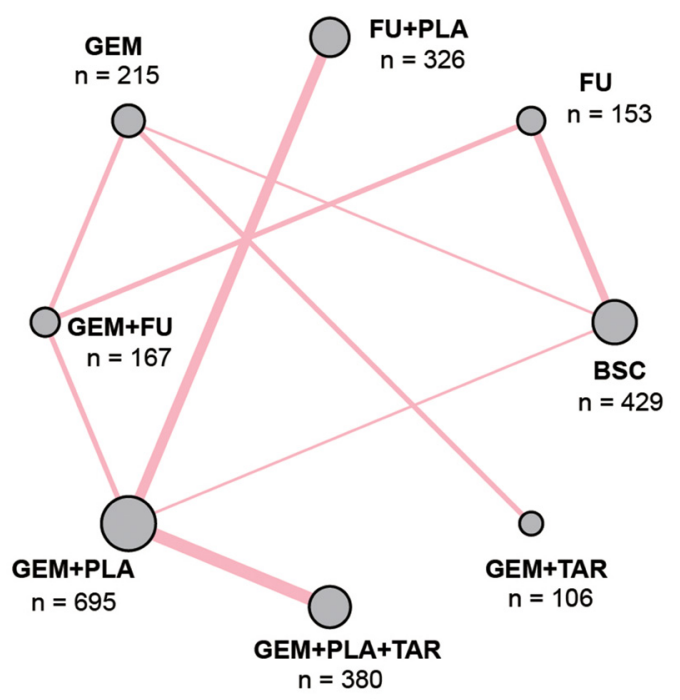

Figure 2: Network plot of included studies. The size of each circle represents the sum of the samples; a solid line represents the direct comparison of the two therapies and the width of each line stands for the number of two-armtrials comparison. Abbreviation: GEM, gemcitabine; PLA, Platinum; FU, fluorouracil; TAR, target agents; BSC, best supportive care. 
Table 1: Characteristics of included studies of biliary tract cancer treatment

\begin{tabular}{|c|c|c|c|c|c|c|c|c|c|c|c|c|}
\hline \multirow[t]{2}{*}{ Study } & \multirow[t]{2}{*}{ Country } & \multirow[t]{2}{*}{ Design } & \multirow[t]{2}{*}{ Follow-up } & \multicolumn{4}{|c|}{ Treatment 1} & \multicolumn{4}{|c|}{ Treatment 2} & \multirow[t]{2}{*}{ Outcomes } \\
\hline & & & & Size & Treatment & Age (range) & Man (\%) & Size & Treatment & Age (range) & Man (\%) & \\
\hline Chen, 2015 & China & $\mathrm{RCT}$ & 27 & 60 & GEM+PLA & $59(32-80)$ & 50 & 62 & $\mathrm{GEM}+\mathrm{PLA}+\mathrm{TAR}$ & $61(32-78)$ & 45 & $\begin{array}{l}(1)(2)(3)(4) \\
(5)(6)(7)(8)\end{array}$ \\
\hline Fiteni, 2014 & France & Retro & 24 & 44 & GEM+PLA & - & 66 & 20 & $\mathrm{GEM}+\mathrm{FU}$ & - & 45 & $\begin{array}{l}(1)(2)(3)(4) \\
(5)(6)(7)(8)\end{array}$ \\
\hline Kang, 2012 & Korea & $\mathrm{RCT}$ & 36 & 49 & GEM+PLA & $59(32-77)$ & 63 & 47 & FU+PLA & $60(36-77)$ & 92 & $\begin{array}{l}(1)(2)(3)(4) \\
(5)(6)(7)(8)\end{array}$ \\
\hline Lee, 2015 & Korea & Retro & 24 & 49 & GEM+PLA & $65(45-81)$ & 63.3 & 44 & FU+PLA & $65(39-80)$ & 68.2 & $\begin{array}{l}(1)(2)(3)(4) \\
(5)(6)(7)(8)\end{array}$ \\
\hline Lee, 2012 & Korea & $\mathrm{RCT}$ & 18 & 133 & GEM+PLA & $61(55-68)$ & 59 & 135 & $\mathrm{GEM}+\mathrm{PLA}+\mathrm{TAR}$ & $59(54-66)$ & 67 & $\begin{array}{l}(1)(2)(3)(4) \\
(5)(6)(7)(8)\end{array}$ \\
\hline Leone, 2016 & Italy & $\mathrm{RCT}$ & 42 & 44 & GEM+PLA & $64(37-79)$ & 34 & 45 & $\mathrm{GEM}+\mathrm{PLA}+\mathrm{TAR}$ & $64(47-79)$ & 37.7 & $\begin{array}{l}(1)(2)(3)(4) \\
(5)(6)(7)(8)\end{array}$ \\
\hline \multirow[t]{2}{*}{$\mathrm{Li}, 2016$} & China & $\mathrm{RCT}$ & 24 & 25 & GEM & - & - & 25 & $\mathrm{GEM}+\mathrm{FU}$ & - & - & $\begin{array}{l}(1)(2)(3)(4) \\
(5)(6)(7)(8)\end{array}$ \\
\hline & & & & 25 & FU & - & - & 25 & $\mathrm{GEM}+\mathrm{FU}$ & - & - & $\begin{array}{l}(1)(2)(3)(4) \\
(5)(6)(7)(8)\end{array}$ \\
\hline Malka, 2014 & France & $\mathrm{RCT}$ & 34 & 74 & GEM+PLA & $62(39-75)$ & 57 & 76 & $\mathrm{GEM}+\mathrm{PLA}+\mathrm{TAR}$ & $61(35-75)$ & 57 & $\begin{array}{l}(1)(2)(3)(4) \\
(5)(6)(7)(8)\end{array}$ \\
\hline Moehler, 2014 & Germany & RCT & 31 & 49 & GEM+TAR & $64(44-83)$ & 59 & 48 & GEM & $65(36-84)$ & 52 & $\begin{array}{l}(1)(2)(3)(4) \\
(5)(6)(7)(8)\end{array}$ \\
\hline Morizane, 2013 & Japan & RCT & 24 & 51 & $\mathrm{GEM}+\mathrm{FU}$ & $66(39-78)$ & 52.9 & 50 & FU & $63(49-79)$ & 56 & $\begin{array}{c}(1)(2)(3)(5) \\
(6)(7)(8)\end{array}$ \\
\hline Phelip, 2014 & France & RCT & 30 & 18 & FU+PLA & $70(53-80)$ & 39 & 16 & GEM+PLA & $75(54-81)$ & 50 & $(1)(2)(7)$ \\
\hline Rogers, 2014 & USA & Retro & 60 & 11 & GEM+PLA & - & - & 16 & $\mathrm{GEM}+\mathrm{FU}$ & - & - & $(1)(2)$ \\
\hline Santoro, 2015 & Italy & RCT & 33 & 57 & GEM+TAR & $(55-74)$ & 53.4 & 52 & GEM & $(55-73)$ & 44.6 & $\begin{array}{c}(1)(2)(3)(4) \\
(5)(6)(7)\end{array}$ \\
\hline Sasaki, 2013 & Japan & $\mathrm{RCT}$ & 24 & 30 & GEM+FU & $68(47-83)$ & 53 & 32 & GEM & $75(55-86)$ & 63 & $\begin{array}{l}(1)(2)(3)(4) \\
(5)(6)(7)(8)\end{array}$ \\
\hline \multirow[t]{2}{*}{ Sharma, 2010} & India & RCT & 27 & 28 & $\mathrm{FU}$ & 47 & 18 & 27 & $\mathrm{BSC}$ & 51 & 22 & $\begin{array}{c}(1)(2)(3) \\
(4)(5)\end{array}$ \\
\hline & & & & 26 & GEM+PLA & 49 & 19 & 27 & $\mathrm{BSC}$ & 51 & 22 & $\begin{array}{c}(1)(2)(3) \\
(4)(5)\end{array}$ \\
\hline Valle, 2015 & UK & RCT & 36 & 62 & GEM+PLA+ & $68(60-73)$ & 55 & 62 & GEM+PLA & $65(60-73)$ & 45 & $\begin{array}{l}(1)(2)(3)(4) \\
(5)(6)(7)(8)\end{array}$ \\
\hline Woo, 2014 & Korea & Retro & 45 & 127 & GEM+PLA & $62(35-76)$ & 56.7 & 217 & FU+PLA & $58(27-82)$ & 62.8 & $\begin{array}{c}(1)(2)(3)(4) \\
(5)(6)\end{array}$ \\
\hline \multirow[t]{3}{*}{ Yonemoto, 2007} & Japan & Retro & 52 & 30 & FU & - & 43 & 125 & BSC & - & 61 & $(1)(2)(3)(4)$ \\
\hline & & & & 20 & FU & - & 65 & 125 & $\mathrm{BSC}$ & - & 61 & $(1)(2)(3)(4)$ \\
\hline & & & & 58 & GEM & - & 52 & 125 & BSC & - & 61 & $(1)(2)(3)(4)$ \\
\hline
\end{tabular}

Abbreviation: RCT, randomized controlled trial; Retro, retrospective trial; GEM, gemcitabine; PLA, Platinum; FU, fluorouracil; TAR, target agents; BSC, best supportive care; Outcomes: (1) overall survival; (2) progression-free survival; (3) overall response rate; (4) disease control rate; (5) vomiting; (6) nausea; (7) neutropenia; (8) thrombocytopenia

$\mathrm{OR}=0.05,95 \% \mathrm{CrI}=0.01-0.67 ; \mathrm{GEM}+\mathrm{PLA}$ vs. GEM+FU: $\mathrm{OR}=0.02, \quad 95 \% \mathrm{CrI}=0.01-0.25 ; \quad \mathrm{GEM}+\mathrm{PLA}+\mathrm{TAR}$ vs. GEM+FU: $\quad \mathrm{OR}=0.04, \quad 95 \% \mathrm{CrI}=0.01-0.44) . \quad$ As for thrombocytopenia, FU+PLA significantly reduced the toxicity compared to $\mathrm{GEM}(\mathrm{OR}=0.01,95 \% \mathrm{CrI}=0.01$ $0.64), \quad \mathrm{GEM}+\mathrm{FU}(\mathrm{OR}=0.01,95 \% \mathrm{CrI}=0.01-0.25)$ and
GEM+TAR $\quad(\mathrm{OR}=0.01, \quad 95 \% \mathrm{CrI}=0.01-0.86), \quad$ while $\mathrm{GEM}+\mathrm{FU}$ increased the risk compared to GEM+PLA $(\mathrm{OR}=53.52,95 \% \mathrm{CrI}=2.66-2465.13)$ and $\mathrm{GEM}+\mathrm{PLA}+\mathrm{TAR}$ $(\mathrm{OR}=33.78, \quad 95 \% \mathrm{CrI}=1.23-1826.21)$. Besides, no significant results were detected with respect to nausea and vomiting. 


\section{Ranking}

According to SUCRAs presented in Table 4 , GEM+PLA+TAR ranked the first in all survival terms, while FU+PLA showed an excellent control of adverse events. GEM+PLA also exhibited relative better performance in all terms. Besides, GEM+FU was outstanding in terms of DCR, GEM+TAR showed a good control of nausea while FU was associated with relative low risk of neutropenia. Generally, treatments containing PLA showed superiority concerning both efficacy and safety outcomes and were more recommended than those without PLA.

\section{DISCUSSION}

This NMA was designed to address the problem whether the addition of platinum and targeted drugs to GEM or FU based chemotherapy regimens can improve efficacy while reduce toxicity, and furthermore, serve as a reference to clinical practice. A total of 7 drug-containing treatments and $\mathrm{BSC}$ were compared with respect to their efficacy and safety.

First of all, according to SUCRA rankings, the addition of PLA to standard chemotherapy did improve the effect on survival and moreover, lower the risk of adverse events, which is consistent to the results of most studies. For example, a meta-analysis conducted by Yang et al. [28] reported that all survival outcomes were significantly more favorable for patients treated with GEM+PLA than those with GEM alone, while another systematic review conducted by Park [29] suggested that the adverse events associated with GEM+PLA were generally more acceptable and manageable. However, according to this NMA, some exceptions existed. For instance, the addition of PLA to GEM seemed to dilute DCR, while the addition of PLA to GEM+TAR appeared to increase the control of disease, which might be caused by the lack of direct evidence.

Secondly, the effect of TAR was also confirmed in this NMA. According to SUCRA, the addition of TAR to GEM+PLA improved all survival outcomes and was associated with increased ORR, DCR and higher risk of adverse effects. Similar results were reported in previous studies. For example, an RCT conducted by Chen et al. [9] concluded that the addition of cetuximab to GEM+PLA could significantly improve PFS. However, the addition of TAR to GEM+PLA seemed to mildly increase the adverse events of chemotherapy, and this effect was also confirmed in previous studies. A trial designed by Valle [13] reported that patients treated with cediranib plus GEM+PLA had more adverse events. Thus, the toxicity of TAR should be noted before putting it into use. Moreover, due to the lack of evidence, the effect of TAR added to GEM remained unclear, and further investigations should be made to reach a definite conclusion.

In addition to evaluating the role of TAR and PLA, some other observations were made in this NMA. Firstly, treatments containing GEM were more efficacious than those with FU. For instance, GEM and GEM+PLA yielded more desirable survival outcomes than FU and FU+PLA respectively. In the meantime, treatments containing FU were associated with less adverse events. Similar results were obtained in other articles. A study conducted by Kang [25] recorded that more adverse events were reported from patients treated with GEM+PLA than those with FU+PLA.
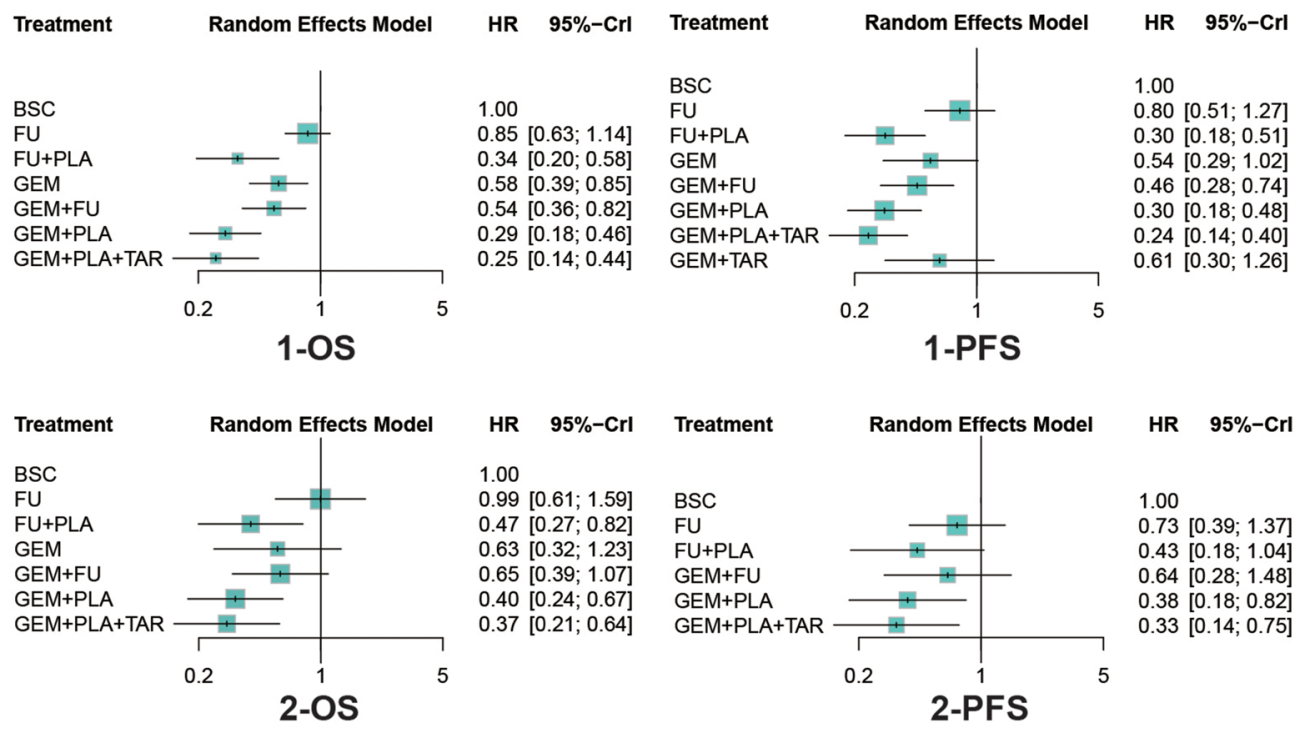

Figure 3: Forest plots of survival outcomes. Hazard ratios (HRs) and 95\% credible interval (CrIs) indicate the relative efficacy under the corresponding endpoint. Abbreviation: GEM, gemcitabine; PLA, Platinum; FU, fluorouracil; TAR, target agents; BSC, best supportive care; OS, overall survival; PFS, progression free survival. 
Table 2: Network comparison of prognostic and response outcomes of different therapies for biliary tract cancer treatments

\begin{tabular}{|c|c|c|c|c|c|c|c|c|c|}
\hline \multirow[t]{7}{*}{ 1-OS } & BSC & $0.99(0.61,1.59)$ & $0.47(0.27,0.82)$ & $0.63(0.32,1.23)$ & $0.65(0.39,1.07)$ & $0.40(0.24,0.67)$ & $0.37(0.21,0.64)$ & & \multirow[t]{7}{*}{ 2-OS } \\
\hline & $0.85(0.63,1.14)$ & FU & $0.48(0.29,0.77)$ & $0.63(0.35,1.14)$ & $0.65(0.45,0.95)$ & $0.41(0.26,0.62)$ & $0.37(0.23,0.60)$ & & \\
\hline & $0.34(0.20,0.58)$ & $0.40(0.23,0.69)$ & FU+PLA & $1.33(0.76,2.32)$ & $1.37(0.98,1.92)$ & $0.85(0.68,1.07)$ & $0.78(0.56,1.08)$ & & \\
\hline & $0.58(0.39,0.85)$ & $0.68(0.43,1.07)$ & $1.72(0.96,3.07)$ & GEM & $0.97(0.62,1.51)$ & $0.62(0.49,0.79)$ & $0.57(0.40,0.80)$ & & \\
\hline & $0.54(0.36,0.82)$ & $0.64(0.42,0.97)$ & $1.62(1.07,2.44)$ & $0.94(0.60,1.47)$ & GEM+FU & $1.56(0.94,2.60)$ & $0.91(0.72,1.16)$ & & \\
\hline & $0.29(0.18,0.46)$ & $0.34(0.21,0.54)$ & $0.85(0.65,1.12)$ & $0.50(0.30,0.83)$ & $0.53(0.39,0.72)$ & GEM+PLA & $1.71(0.98,3.00)$ & & \\
\hline & $0.25(0.14,0.44)$ & $0.30(0.17,0.53)$ & $0.75(0.50,1.13)$ & $0.44(0.24,0.79)$ & $0.46(0.30,0.72)$ & $0.88(0.65,1.20)$ & GEM+PLA+TAR & & \\
\hline \multirow[t]{8}{*}{ 1-PFS } & BSC & $0.73(0.39,1.37)$ & $0.43(0.18,1.04)$ & - & $0.64(0.28,1.48)$ & $0.38(0.18,0.82)$ & $0.33(0.14,0.75)$ & - & \multirow[t]{8}{*}{ 2-PFS } \\
\hline & $0.80(0.51,1.27)$ & FU & $0.59(0.20,1.74)$ & - & $0.88(0.31,2.51)$ & $0.52(0.19,1.41)$ & $0.45(0.16,1.27)$ & - & \\
\hline & $0.30(0.18,0.51)$ & $0.37(0.26,0.53)$ & FU+PLA & - & $1.49(0.88,2.54)$ & $0.88(0.58,1.34)$ & $0.76(0.45,1.27)$ & - & \\
\hline & $0.54(0.29,1.02)$ & $0.68(0.42,1.09)$ & $1.82(1.14,2.92)$ & GEM & - & - & - & - & \\
\hline & $0.46(0.28,0.74)$ & $0.57(0.44,0.73)$ & $1.53(1.19,1.96)$ & $0.84(0.56,1.25)$ & GEM+FU & $0.59(0.43,0.82)$ & $0.51(0.33,0.79)$ & - & \\
\hline & $0.30(0.18,0.48)$ & $0.37(0.28,0.49)$ & $0.99(0.80,1.22)$ & $0.54(0.36,0.83)$ & $0.65(0.56,0.75)$ & GEM+PLA & $0.86(0.64,1.16)$ & - & \\
\hline & $0.24(0.14,0.40)$ & $0.30(0.21,0.42)$ & $0.80(0.61,1.05)$ & $0.44(0.28,0.69)$ & $0.53(0.42,0.66)$ & $0.81(0.68,0.96)$ & GEM+PLA+TAR & & \\
\hline & $0.61(0.30,1.26)$ & $0.77(0.42,1.38)$ & $2.05(1.14,3.70)$ & $1.13(0.79,1.61)$ & $1.35(0.79,2.29)$ & $2.07(1.19,3.60)$ & $2.56(1.44,4.57)$ & GEM+TAR & \\
\hline \multirow[t]{8}{*}{ ORR } & BSC & $0.32(0.08,1.17)$ & $1.09(0.28,4.53)$ & $2.61(0.57,12.18)$ & $1.13(0.34,3.82)$ & $1.90(0.53,7.32)$ & $0.98(0.12,7.54)$ & $1.45(0.24,8.94)$ & \multirow[t]{8}{*}{ DCR } \\
\hline & $4.39(0.57,56.26)$ & FU & $3.42(0.68,18.73)$ & $8.00(2.08,35.52)$ & $3.56(0.76,16.12)$ & $5.93(1.23,29.96)$ & $3.00(0.43,22.20)$ & $4.44(0.84,25.79)$ & \\
\hline & $27.66(3.25,572.49)$ & $6.36(0.59,94.63)$ & FU + PLA & $2.39(0.53,10.49)$ & $1.03(0.53,1.82)$ & $1.73(0.78,3.71)$ & $0.90(0.11,6.36)$ & $1.34(0.22,7.69)$ & \\
\hline & $14.88(1.73,214.86)$ & $3.39(1.14,11.02)$ & $0.54(0.04,5.10)$ & GEM+FU & $0.43(0.11,1.67)$ & $0.73(0.17,3.06)$ & $0.37(0.09,1.45)$ & $0.55(0.21,1.45)$ & \\
\hline & $20.29(2.64,361.41)$ & $4.66(0.49,57.97)$ & $0.74(0.29,1.58)$ & $1.35(0.16,15.49)$ & GEM+PLA & $1.68(1.07,2.80)$ & $0.87(0.12,5.81)$ & $1.30(0.25,6.96)$ & \\
\hline & $40.85(4.85,780.55)$ & $9.39(0.91,126.47)$ & $1.49(0.48,3.94)$ & $2.72(0.30,34.12)$ & $1.99(1.08,3.78)$ & GEM+PLA+TAR & $0.51(0.07,3.56)$ & $0.77(0.14,4.31)$ & \\
\hline & $10.70(0.64,252.14)$ & $2.39(0.31,19.89)$ & $0.37(0.02,6.75)$ & $0.71(0.12,4.01)$ & $0.51(0.03,8.41)$ & $0.25(0.01,4.53)$ & GEM+TAR & $1.51(0.56,4.06)$ & \\
\hline & $7.24(0.59,129.02)$ & $1.62(0.30,8.85)$ & $0.26(0.01,3.32)$ & $0.48(0.13,1.62)$ & $0.35(0.02,4.06)$ & $0.18(0.01,2.18)$ & $0.67(0.20,2.23)$ & GEM & \\
\hline
\end{tabular}

Abbreviation: BSC, best supportive care; GEM, gemcitabine; OXA, Oxaliplatin; CIS, Cisplatin; PLA, Platinum; FU, fluorouracil; TAR, targeted drugs; OS, overall survival; $\mathrm{PFS}$, progression free survival; ORR, overall response rate; DCR, disease control rate. The data is in the form of hazard ratio (HR) and corresponding $95 \%$ credible intervals (CrI) for 1-OS, 2-OS, 1-PFS and 2-PFS and in the form of odds ratio (OR) and corresponding 95\% CrI for ORR and DCR.

Another study designed by Lee [15] suggested that GEM+PLA resulted in a superior response rate compared to FU+PLA. Secondly, the addition of FU to GEM showed little superiority to GEM in both survival outcomes and adverse events, which was also confirmed in a previous study [12].

As the first NMA comprehensively judged chemotherapy treatments of BTC, we systematically analyzed the efficacy and adverse effect of several treatments. Although conducted as meticulously as possible, this NMA still had some limitations. First of all, the treatment FU actually referred to different FU-based or FU-related drugs, including S-1, capecitabine and FU itself. S-1 is a fourth generation oral fluropyrimidine prodrug that 5-chloro-2, 4-dihydropyrimidine (CDHP, a dihydropyrimidine dehydrogenase inhibitor) and potassium oxonate, part of which translates into $\mathrm{FU}$ after entering human body [30], while capecitabine is an oral fluropyrimidine, which can also be metabolically converted into FU in the body. Although no significant statistical difference was detected among the three drugs in treating gastric cancer [31,32], it remains unclear whether they have different effects on patients with BTC. Second, the treatment TAR also included several targeted drugs, including cetuximab, erlotinib, panitumumab, vandetanib, cediranib and sorafenib. The effects of targeted drugs may differ from each other. For example, a study conducted by Moehler [19] reported that the addition of sorafenib to GEM did not demonstrate improved efficacy while as mentioned before, the survival effect of cetuximab has been confirmed in previous study [9]. To further analyze the effect of different targeted drugs, more detailed classification should be made in future studies. Thirdly, PLA in this NMA includes CIS and OXA. In fact, the difference has already been reported between GEM+ CIS and GEM+OXA [33], which may result in the 
Table 3: Network comparison of adverse events of different therapies for biliary tract cancer

\begin{tabular}{|c|c|c|c|c|c|c|c|c|}
\hline \multirow[t]{7}{*}{ Neutropenia } & FU & $0.16(0.00,4.71)$ & $0.59(0.08,3.53)$ & $1.11(0.25,3.97)$ & $0.17(0.00,4.14)$ & $0.20(0.00,5.93)$ & $0.24(0.02,3.00)$ & \multirow[t]{7}{*}{ Nausea } \\
\hline & $0.43(0.01,8.50)$ & FU+PLA & $3.71(0.12,149.90)$ & $6.69(0.30,239.85)$ & $1.04(0.38,2.75)$ & $1.26(0.30,5.05)$ & $1.52(0.03,90.02)$ & \\
\hline & $13.46(2.18,88.23)$ & $31.50(1.97,1863.11)$ & GEM & $1.82(0.50,7.54)$ & $0.28(0.01,7.39)$ & $0.34(0.01,10.28)$ & $0.42(0.07,2.14)$ & \\
\hline & $27.39(7.32,132.95)$ & $65.37(5.05,3261.69)$ & $2.05(0.66,6.82)$ & GEM+FU & $0.16(0.00,2.94)$ & $0.19(0.01,4.10)$ & $0.23(0.02,1.86)$ & \\
\hline & $0.66(0.01,11.36)$ & $1.49(0.63,4.18)$ & $0.05(0.00,0.67)$ & $0.02(0.00,0.25)$ & GEM+PLA & $1.21(0.42,3.32)$ & $1.46(0.04,79.04)$ & \\
\hline & $1.03(0.01,19.69)$ & $2.36(0.78,8.67)$ & $0.08(0.00,1.21)$ & $0.04(0.00,0.44)$ & $1.58(0.77,3.39)$ & GEM+PLA+TAR & $1.22(0.03,75.94)$ & \\
\hline & $7.77(0.76,75.94)$ & $18.17(0.76,1366.49)$ & $0.57(0.14,2.18)$ & $0.27(0.04,1.60)$ & $11.82(0.58,788.40)$ & $7.54(0.33,544.57)$ & GEM+TAR & \\
\hline \multirow[t]{7}{*}{ Thrombocytopenia } & FU & $0.14(0.00,3.42)$ & $1.62(0.18,15.18)$ & $1.97(0.42,10.59)$ & $0.20(0.00,4.31)$ & $0.14(0.00,3.56)$ & $1.57(0.09,29.08)$ & \multirow[t]{7}{*}{ Vomiting } \\
\hline & $0.04(0.00,2.48)$ & FU+PLA & $12.55(0.55,713.37)$ & $14.59(0.96,692.29)$ & $1.49(0.58,4.22)$ & $1.02(0.26,4.06)$ & $11.70(0.32,1130.03)$ & \\
\hline & $3.16(0.20,59.15)$ & $76.71(1.55,7863.60)$ & GEM & $1.21(0.25,5.47)$ & $0.12(0.00,2.66)$ & $0.08(0.00,2.16)$ & $0.96(0.14,6.55)$ & \\
\hline & $4.90(0.65,46.53)$ & $120.30(3.97,8518.54)$ & $1.58(0.25,10.38)$ & GEM+FU & $0.10(0.00,1.32)$ & $0.07(0.00,1.06)$ & $0.79(0.07,9.68)$ & \\
\hline & $0.09(0.00,4.06)$ & $2.16(0.41,14.88)$ & $0.03(0.00,1.02)$ & $0.02(0.00,0.38)$ & GEM+PLA & $0.68(0.26,1.73)$ & $7.77(0.22,639.06)$ & \\
\hline & $0.15(0.00,8.41)$ & $3.42(0.47,37.34)$ & $0.05(0.00,2.10)$ & $0.03(0.00,0.81)$ & $1.58(0.49,5.70)$ & GEM+PLA+TAR & $11.82(0.28,1118.79)$ & \\
\hline & $5.00(0.11,259.82)$ & $123.97(1.16,26108.08)$ & $1.60(0.11,22.65)$ & $1.00(0.04,25.79)$ & $55.70(0.67,8103.08)$ & $35.16(0.34,5710.15)$ & GEM+TAR & \\
\hline
\end{tabular}

Abbreviation: GEM, gemcitabine; PLA, Platinum; FU, fluorouracil; TAR, targeted drugs. The data is in the form of odds ratio (OR) and corresponding 95\% credible intervals (CrI).

heterogeneity of this study. Finally, the lack of evidence led to some missing information of some treatments. For example, 3 out of 4 survival outcomes were missing with respect to the treatment of GEM+TAR. Therefore,
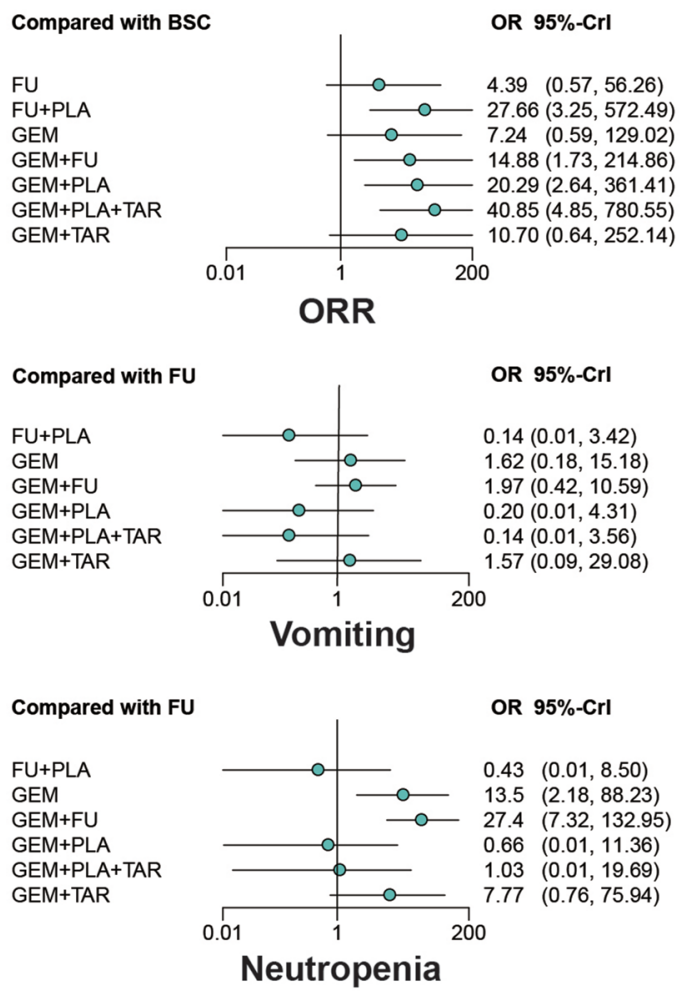

further effort should be made in order to gain a more comprehensive result.

In conclusion, the addition of PLA can significantly improve the efficacy of FU and GEM-based treatments,
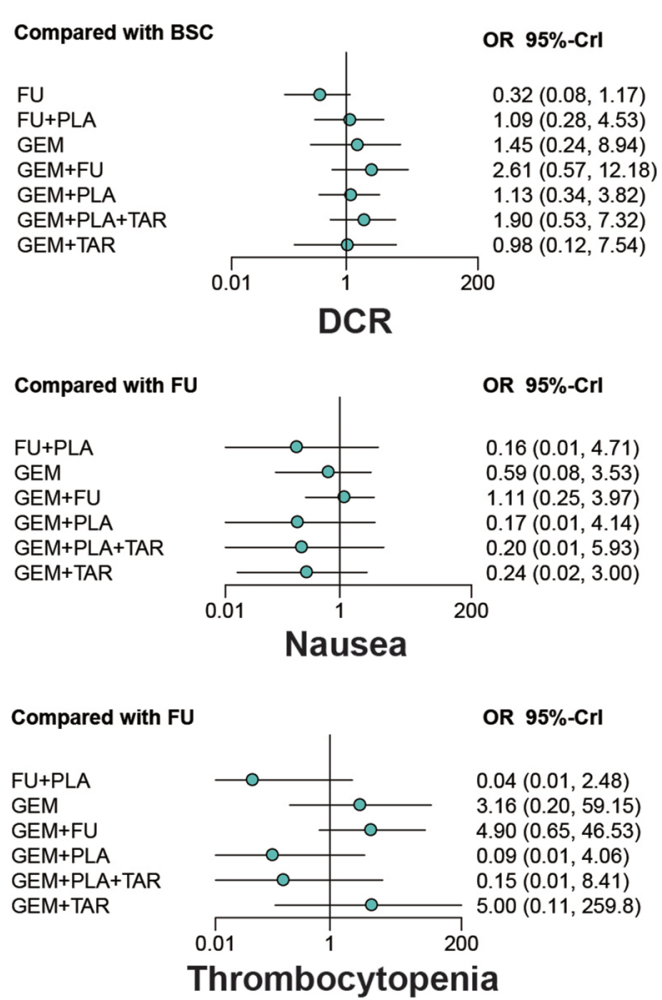

Figure 4: Forest plots of overall response rate (ORR), disease control rate (DCR) and adverse events. Odds ratios (ORs) and $95 \%$ credible interval (CrIs) indicate the relative efficacy or safety under the corresponding endpoint. Abbreviation: GEM, gemcitabine; PLA, Platinum; FU, fluorouracil; TAR, target agents; BSC, best supportive care; ORR, overall response rate; DCR, disease control rate. 
Table 4: SUCRA of different treatments for all outcomes in biliary tract cancer

\begin{tabular}{lccccccccccc}
\hline & 1-OS & 1-PFS & 2-OS & 2-PFS & ORR & DCR & Vomiting & Nausea & Neutropenia & Thrombocytopenia \\
\hline BSC & 0.023 & 0.042 & 0.104 & 0.071 & 0.029 & 0.416 & - & - & - & - \\
FU & 0.155 & 0.152 & 0.099 & 0.316 & 0.226 & 0.049 & 0.411 & 0.234 & 0.692 & 0.483 \\
FU+PLA & 0.694 & 0.787 & 0.660 & 0.631 & 0.748 & 0.437 & 0.841 & 0.712 & 0.907 & 0.945 \\
GEM & 0.398 & 0.409 & 0.439 & - & 0.351 & 0.595 & 0.271 & 0.401 & 0.193 & 0.276 \\
GEM+FU & 0.433 & 0.524 & 0.404 & 0.303 & 0.630 & 0.881 & 0.182 & 0.175 & 0.029 & 0.145 \\
GEM+PLA & 0.848 & 0.790 & 0.851 & 0.757 & 0.603 & 0.448 & 0.661 & 0.706 & 0.768 & 0.797 \\
GEM+PLA+TAR & 0.949 & 0.991 & 0.945 & 0.923 & 0.899 & 0.778 & 0.834 & 0.614 & 0.582 & 0.666 \\
GEM+TAR & - & 0.304 & - & - & 0.515 & 0.397 & 0.300 & 0.657 & 0.330 & 0.188 \\
\hline
\end{tabular}

Abbreviation: BSC, best supportive care; GEM, gemcitabine; OXA, Oxaliplatin; CIS, Cisplatin; PLA, Platinum; FU, fluorouracil; TAR, targeted drugs; OS, overall survival; PFS, progression free survival; ORR, overall response rate; DOR, disease control rate.

and the addition of TAR to GEM+PLA can contribute to further improvement, but with a mild increase of adverse events. Thus, GEM+PLA and GEM+PLA+TAR are both recommended and the option is depended on the conditions of patients. As the first article for the comprehensive comparison of different chemotherapy treatments for BTC, our study could be served as a reference for clinical treat. Furthermore, more detailed analysis should be conducted in order to gain a more comprehensive result.

\section{MATERIALS AND METHODS}

\section{Literature search}

PubMed, Embase, Cochrane Library were searched for potentially eligible publications of related diseases. The following key terms and their synonymous terms were used, including "biliary tract cancer", "fluorouracil", "gemcitabine", and "targeted medicine". In addition, reviews whose data was available were also included. The searching procedure was accomplished by two investigators independently.

\section{Selection criteria}

Eligible studies should meet the following criteria for further analysis: 1) patients should be diagnosed with advanced or unresectable BTC; 2) studies should include at least two of the followingtreatments: BSC, FU, PLA, GEM, TAR; 3) at least one of the included efficacy and adverse effect outcomes should be reported. 4) Studies were RCTs investigating the.comprehensive efficacy and adverse effects of treatments for BTC. Besides, we excluded the duplicate experiments, reviews and case reports from previous analysis and articles.

\section{Data extraction}

Two investigators conducted data extraction respectively. By scanning the eligible records, the fundamental information of these trials was abstracted, including the last name of the first author, publication year, country, study design, follow-up period, treatments, age of patients, male proportions, sample size and outcomes.

\section{Statistical analysis}

Network plot was computed in order to illustrate the comparisons from the included records. The size of each circle represents the sum of the samples; a solid line represents the direct comparison of the two therapies and the width of each line stands for the number of two-arm trials comparison.

Next, a Bayesian framework and Markov Chain Monte Carlo (MCMC) simulations NMA was applied. R 3.2.3 software and STATA 13.0 were used to conduct this analysis. Based on random effects model, hazard ratios (HRs) and 95\% credible intervals (CrIs) were calculated to compare the effects on long-term survival of each different treatments for OS and PFS. While for ORR and DCR, odd ratios (ORs) combined with 95\% CrIs were used to assess the pharmacological effects. Moreover, four adverse events, including vomiting, nausea, neutropenia and thrombocytopenia, were analyzed in terms of OR with corresponding 95\% CrIs to evaluate the relative safety of included treatments. In the end, surface under the cumulative ranking curve (SUCRA) was calculated to obtain the rankings of different BTC treatments.

\section{Abbreviations}

BTC, biliary tract cancer

GBC, gallbladder cancer 
ICC, intrahepatic cholangiocarcinoma

ECC, extrahepatic cholangiocarcinoma

HCC, hilar cholangiocarcinoma

BSC, best supportive care

GEM, gemcitabine

FU, fluorouracil

TAR, targeted drugs

OXA, oxaliplatin

CIS, cisplatin

PLA, platinum

OS, overall survival

PFS, progression free survival

ORR, overall response rate

DCR, disease control rate

\section{Author contributions}

Research conception and design: Quan-Xing Ge and Er-Dong Shen; Data collection and screening: XinFang Sun and Zhi-Kuan He; Drafting of the manuscript: Xin-Fang Sun, Zhi-Kuan He and Jin-Ping Sun; Critical revision of the manuscript: Quan-Xing Ge and Er-Dong Shen; Approval of final manuscript: All authors.

\section{ACKNOWLEDGMENTS}

We would like to acknowledge the reviewers for their helpful comments on this paper.

\section{CONFLICTS OF INTEREST}

The authors have no relevant conflicts of interest to disclose.

\section{FUNDING}

This research did not receive any specific grant from funding agencies in the public, commercial, or not-forprofit sectors.

\section{REFERENCES}

1. Owen PA, Allery LA, Harding KG, Hayes TM. General practitioners' continuing medical education within and outside their practice. BMJ. 1989; 299: 238-40.

2. Mayo SC, Shore AD, Nathan H, Edil B, Wolfgang CL, Hirose K, Herman J, Schulick RD, Choti MA, Pawlik TM. National trends in the management and survival of surgically managed gallbladder adenocarcinoma over 15 years: a population-based analysis. J Gastrointest Surg. 2010; 14: 1578-91. https://doi.org/10.1007/ s11605-010-1335-3.

3. Yang L, Shan J, Shan L, Saxena A, Bester L, Morris DL. Trans-arterial embolisation therapies for unresectable intrahepatic cholangiocarcinoma: a systematic review.
J Gastrointest Oncol. 2015; 6: 570-88. https://doi. org/10.3978/j.issn.2078-6891.2015.055.

4. Eckel F, Schmid RM. Chemotherapy and targeted therapy in advanced biliary tract carcinoma: a pooled analysis of clinical trials. Chemotherapy. 2014; 60: 13-23. https://doi. org/10.1159/000365781.

5. Ducreux M, Rougier P, Fandi A, Clavero-Fabri MC, Villing AL, Fassone F, Fandi L, Zarba J, Armand JP. Effective treatment of advanced biliary tract carcinoma using 5-fluorouracil continuous infusion with cisplatin. Ann Oncol. 1998; 9: 653-6.

6. Valle J, Wasan H, Palmer DH, Cunningham D, Anthoney A, Maraveyas A, Madhusudan S, Iveson T, Hughes S, Pereira SP, Roughton M, Bridgewater J. Cisplatin plus gemcitabine versus gemcitabine for biliary tract cancer. $\mathrm{N}$ Engl J Med. 2010; 362: 1273-81. https://doi.org/10.1056/ NEJMoa0908721.

7. Lee CS, Pirdas A. Epidermal growth factor receptor immunoreactivity in gallbladder and extrahepatic biliary tract tumours. Pathol Res Pract. 1995; 191: 1087-91. https:// doi.org/10.1016/S0344-0338(11)80652-7.

8. Gruenberger B, Schueller J, Heubrandtner U, Wrba F, Tamandl D, Kaczirek K, Roka R, Freimann-Pircher S, Gruenberger T. Cetuximab, gemcitabine, and oxaliplatin in patients with unresectable advanced or metastatic biliary tract cancer: a phase 2 study. Lancet Oncol. 2010; 11: 11428. https://doi.org/10.1016/S1470-2045(10)70247-3.

9. Chen JS, Hsu C, Chiang NJ, Tsai CS, Tsou HH, Huang SF, Bai LY, Chang IC, Shiah HS, Ho CL, Yen CJ, Lee $\mathrm{KD}$, Chiu $\mathrm{CF}$, et al. A KRAS mutation status-stratified randomized phase II trial of gemcitabine and oxaliplatin alone or in combination with cetuximab in advanced biliary tract cancer. Ann Oncol. 2015; 26: 943-9. https://doi. org/10.1093/annonc/mdv035.

10. Okusaka T, Nakachi K, Fukutomi A, Mizuno N, Ohkawa S, Funakoshi A, Nagino M, Kondo S, Nagaoka S, Funai J, Koshiji M, Nambu Y, Furuse J, et al. Gemcitabine alone or in combination with cisplatin in patients with biliary tract cancer: a comparative multicentre study in Japan. Br J Cancer. 2010; 103: 469-74. https://doi.org/10.1038/ sj.bjc. 6605779 .

11. Li H, Zhang ZY, Zhou ZQ, Guan J, Tong DN, Zhou GW. Combined gemcitabine and S-1 chemotherapy for treating unresectable hilar cholangiocarcinoma: a randomized openlabel clinical trial. Oncotarget. 2016; 7:26888-97. https://doi.org/10.18632/oncotarget.8590.

12. Leone F, Marino D, Cereda S, Filippi R, Belli C, Spadi R, Nasti G, Montano M, Amatu A, Aprile G, Cagnazzo C, Fasola G, Siena S, et al. Panitumumab in combination with gemcitabine and oxaliplatin does not prolong survival in wild-type KRAS advanced biliary tract cancer: A randomized phase 2 trial (Vecti-BIL study). Cancer. 2016; 122: 574-81. https://doi.org/10.1002/cncr.29778.

13. Valle JW, Wasan H, Lopes A, Backen AC, Palmer DH, Morris K, Duggan M, Cunningham D, Anthoney DA, 
Corrie P, Madhusudan S, Maraveyas A, Ross PJ, et al. Cediranib or placebo in combination with cisplatin and gemcitabine chemotherapy for patients with advanced biliary tract cancer (ABC-03): a randomised phase 2 trial. Lancet Oncol. 2015; 16: 967-78. https://doi.org/10.1016/ S1470-2045(15)00139-4.

14. Santoro A, Gebbia V, Pressiani T, Testa A, Personeni N, Arrivas Bajardi E, Foa P, Buonadonna A, Bencardino K, Barone C, Ferrari D, Zaniboni A, Tronconi MC, et al. A randomized, multicenter, phase II study of vandetanib monotherapy versus vandetanib in combination with gemcitabine versus gemcitabine plus placebo in subjects with advanced biliary tract cancer: the VanGogh study. Ann Oncol. 2015; 26: 542-7. https://doi.org/10.1093/annonc/ mdu576.

15. Lee J, Hong TH, Lee IS, You YK, Lee MA. Comparison of the Efficacy between Gemcitabine-Cisplatin and Capecitabine-Cisplatin Combination Chemotherapy for Advanced Biliary Tract Cancer. Cancer Res Treat. 2015; 47: 259-65. https://doi.org/10.4143/crt.2013.230.

16. Woo SM, Lee WJ, Kim JH, Kim DH, Han SS, Park SJ, Kim TH, Lee JH, Koh YH, Hong EK. Gemcitabine plus cisplatin versus capecitabine plus cisplatin as first-line chemotherapy for advanced biliary tract cancer: A retrospective cohort study. Chemotherapy. 2014; 59: 232-8.

17. Rogers JE, Law L, Nguyen VD, Qiao W, Javle MM, Kaseb A, Shroff RT. Second-line systemic treatment for advanced cholangiocarcinoma. J Gastrointest Oncol. 2014; 5: 408-13. https://doi.org/10.3978/j.issn.2078-6891.2014.072.

18. Phelip JM, Vendrely V, Rostain F, Subtil F, Jouve JL, Gasmi M, Michel P, Le Malicot K, Smith D, Seitz JF, Fauchart JP, Martin P, Bennouna J, et al. Gemcitabine plus cisplatin versus chemoradiotherapy in locally advanced biliary tract cancer: Federation Francophone de Cancerologie Digestive 9902 phase II randomised study. Eur J Cancer. 2014; 50: 2975-82. https://doi.org/10.1016/j.ejca.2014.08.013.

19. Moehler M, Maderer A, Schimanski C, Kanzler S, Denzer U, Kolligs FT, Ebert MP, Distelrath A, Geissler M, Trojan J, Schutz M, Berie L, Sauvigny C, et al. Gemcitabine plus sorafenib versus gemcitabine alone in advanced biliary tract cancer: a double-blind placebo-controlled multicentre phase II AIO study with biomarker and serum programme. Eur J Cancer. 2014; 50: 3125-35. https://doi.org/10.1016/j. ejca.2014.09.013.

20. Malka D, Cervera P, Foulon S, Trarbach T, de la Fouchardiere C, Boucher E, Fartoux L, Faivre S, Blanc JF, Viret F, Assenat E, Seufferlein T, Herrmann $\mathrm{T}$, et al. Gemcitabine and oxaliplatin with or without cetuximab in advanced biliary-tract cancer (BINGO): a randomised, open-label, non-comparative phase 2 trial. Lancet Oncol. 2014; 15: 819-28. https://doi.org/10.1016/ s1470-2045(14)70212-8.

21. Fiteni F, Jary M, Monnien F, Nguyen T, Beohou E, Demarchi M, Dobi E, Fein F, Cleau D, Fratte S, Nerich V, Bonnetain F, Pivot X, et al. Advanced biliary tract carcinomas: a retrospective multicenter analysis of first and second-line chemotherapy. BMC Gastroenterol. 2014; 14: 143. https://doi.org/10.1186/1471-230X-14-143.

22. Sasaki T, Isayama H, Nakai Y, Ito Y, Yasuda I, Toda N, Kogure H, Hanada K, Maguchi H, Sasahira N, Kamada H, Mukai T, Okabe Y, et al. A randomized phase II study of gemcitabine and S-1 combination therapy versus gemcitabine monotherapy for advanced biliary tract cancer. Cancer Chemother Pharmacol. 2013; 71: 973-9. https://doi. org/10.1007/s00280-013-2090-4.

23. Morizane C, Okusaka T, Mizusawa J, Takashima A, Ueno M, Ikeda M, Hamamoto Y, Ishii H, Boku N, Furuse J. Randomized phase II study of gemcitabine plus S-1 versus S-1 in advanced biliary tract cancer: a Japan Clinical Oncology Group trial (JCOG 0805). Cancer Sci. 2013; 104: 1211-6. https://doi.org/10.1111/cas.12218.

24. Lee J, Park SH, Chang HM, Kim JS, Choi HJ, Lee MA, Jang JS, Jeung HC, Kang JH, Lee HW, Shin DB, Kang HJ, Sun JM, et al. Gemcitabine and oxaliplatin with or without erlotinib in advanced biliary-tract cancer: a multicentre, open-label, randomised, phase 3 study. Lancet Oncol. 2012; 13: 181-8. https://doi.org/10.1016/s1470-2045(11)70301-1.

25. Kang MJ, Lee JL, Kim TW, Lee SS, Ahn S, Park DH, Lee SS, Seo DW, Lee SK, Kim MH. Randomized phase II trial of S-1 and cisplatin versus gemcitabine and cisplatin in patients with advanced biliary tract adenocarcinoma. Acta Oncol. 2012; 51: 860-6. https://doi.org/10.3109/02841 86X.2012.682628.

26. Sharma A, Dwary AD, Mohanti BK, Deo SV, Pal S, Sreenivas V, Raina V, Shukla NK, Thulkar S, Garg P, Chaudhary SP. Best supportive care compared with chemotherapy for unresectable gall bladder cancer: a randomized controlled study. J Clin Oncol. 2010; 28: 45816. https://doi.org/10.1200/JCO.2010.29.3605.

27. Yonemoto N, Furuse J, Okusaka T, Yamao K, Funakoshi A, Ohkawa S, Boku N, Tanaka K, Nagase M, Saisho H, Sato T. A multi-center retrospective analysis of survival benefits of chemotherapy for unresectable biliary tract cancer. Jpn J Clin Oncol. 2007; 37: 843-51. https://doi.org/10.1093/jjco/ hym 116.

28. Yang R, Wang B, Chen YJ, Li HB, Hu JB, Zou SQ. Efficacy of gemcitabine plus platinum agents for biliary tract cancers: a meta-analysis. Anticancer Drugs. 2013; 24: 8717. https://doi.org/10.1097/CAD.0b013e3283637292.

29. Park JO, Oh DY, Hsu C, Chen JS, Chen LT, Orlando M, Kim JS, Lim HY. Gemcitabine Plus Cisplatin for Advanced Biliary Tract Cancer: A Systematic Review. Cancer Res Treat. 2015; 47: 343-61. https://doi.org/10.4143/ crt.2014.308.

30. Tatsumi K, Fukushima M, Shirasaka T, Fujii S. Inhibitory effects of pyrimidine, barbituric acid and pyridine derivatives on 5-fluorouracil degradation in rat liver extracts. Jpn J Cancer Res. 1987; 78: 748-55.

31. Kim YS, Sym SJ, Park SH, Park I, Hong J, Ahn HK, Park J, Cho EK, Lee WK, Chung M, Lee JH, Shin DB. 
A randomized phase II study of weekly docetaxel/cisplatin versus weekly docetaxel/oxaliplatin as first-line therapy for patients with advanced gastric cancer. Cancer Chemother Pharmacol. 2014; 73: 163-9. https://doi.org/10.1007/ s00280-013-2334-3.

32. Boku N, Yamamoto S, Fukuda H, Shirao K, Doi T, Sawaki A, Koizumi W, Saito H, Yamaguchi K, Takiuchi H, Nasu J, Ohtsu A, Gastrointestinal Oncology Study Group of the Japan Clinical Oncology Group. Fluorouracil versus combination of irinotecan plus cisplatin versus S-1 in metastatic gastric cancer: a randomised phase 3 study. Lancet Oncol. 2009; 10: 1063-9. https://doi.org/10.1016/ S1470-2045(09)70259-1.

33. Fiteni F, Nguyen T, Vernerey D, Paillard MJ, Kim S, Demarchi M, Fein F, Borg C, Bonnetain F, Pivot X. Cisplatin/gemcitabine or oxaliplatin/gemcitabine in the treatment of advanced biliary tract cancer: a systematic review. Cancer Med. 2014; 3: 1502-11. https://doi. org/10.1002/cam4.299. 